\title{
Interactive comment on "Insights into particulate matter pollution in the North China Plain during wintertime: Local contribution or regional transport?" by Jiarui Wu et al.
}

Jiarui Wu et al.

ligh@ieecas.cn

Received and published: 17 November 2020

The comment was uploaded in the form of a supplement:

https://acp.copernicus.org/preprints/acp-2020-597/acp-2020-597-AC2-supplement.pdf

Interactive comment on Atmos. Chem. Phys. Discuss., https://doi.org/10.5194/acp-2020-597, 2020. 